\title{
Cone calorimetric fire properties and thermal analysis of polyester-banana peduncle fibre composite fused with bio-fire retardant additive
}

\author{
Ernest Mbamalu Ezeh * (D)
}

\begin{abstract}
Background: Lately, thermoplastic and thermoset polymers are integrated with natural fillers to harvest composites. Due to an excellent property profile, these composites find wide applications in engineering fields. This research work aimed to investigate the parameters that influence the thermal degradation of Polyester-Banana peduncle fibrereinforced composite incorporated with cow horn ash particle (CHAp) as a fire retardant additive and optimize the total heat produced for the smaller the better. The major instruments used in this study were cone calorimeter and the thermogravimetric analyser.
\end{abstract}

Result: The parameters considered were time, reinforcement type, and weight per cent of reinforcement material. The composites were made by varying the ratios of CHAp and BPF in the polyester matrix from 0:0, 2.5:2.5, 5:5 and 7.5:7.5 and 10:10 weight per cent. The flammability properties of the developed composites were examined, using a cone calorimeter. The controlling parameters were analysed using the Taguchi robust design method. The ANOVA showed that time had the greatest influence on the total heat release rate (81.72\%). The weight per cent reinforcement type (10.37\%) and reinforcement type (5.28\%) had smaller influences on the heat release rate. The S/N ratio obtained, using optimal testing shows that time had the greatest influence on the total heat release rate, followed by weight per cent of reinforcement type, while reinforcement type had the least influence. The corresponding multiple regression models for total heat released revealed that the total heat release rate increased with an increase in time and reinforcement type and decreased with an increase in weight per cent of the fire retardant additive material.

Conclusion: This work indicated that the parameter design of the Taguchi method provided an efficient methodology for the analyses of the effects of thermal degradation parameters of composites. The controlling parameters of time, the weight of reinforcement material and the type of reinforcement material had significant contributions to the value of heat production during composites thermal decomposition. Time had the greatest contribution, followed by the weight of reinforcement type, and type of reinforcement material.

Keywords: Cow horn ash particle, Composite, Fire retardancy, Thermal property, Taguchi method

*Correspondence: mbamalu06@gmail.com

Department of Chemical Engineering, Caritas University Amoji Nike, Enugu, Nigeria

\section{Background}

In recent years, the use of polymer matrix composites has increased considerably, and its potential demand is expected to grow further. Composite materials currently find their use in applications such as ship frames, electronic devices, parts for helicopters and aircraft, and 
other items. Their weight savings are quite significant compared to structures made from metal, such as ships and aircraft (Nawaz 2011). The design disadvantages of using composites include high material and production costs, anisotropic properties of the material and low resistance to impact damage. Another problem with using composites instead of metals is their high flammability and low resistance to fire. As stated by Nawaz (2011), when composites are used in structural applications such as aircraft, the combustion process poses a high risk; hence, the US Federal Aviation Administration (FAA) enforces strict fire regulations on materials used in passenger aircraft, particularly within the cabin. Most thermoset and thermoplastic composites do not meet the low flammability and toxicity criteria for smoke in such a way that flame retardant epoxies and polymers with lower flammability can be used, but these bring additional costs and, in most cases, poorer mechanical properties (Mouritz and Gibson 2006).

However, there are some drawbacks to the use of natural-based fillers, including low thermal resilience, high flammability, high moisture absorption, poor mechanical properties, etc. (Mochane et al. 2019), particularly in advanced/technical applications. To address these drawbacks, further researches, to improve the engineering properties of the utilization of natural-based fillers in composites manufacture had been undertaken.

Natural fibres are made from numerous renewable materials, such as animals, plants, and minerals. The chemical composition depends on the source of the fibre and varies between different sections, even though they are of the same family or type (Mochane et al. 2019). Their quality relies on their chemical structure, crystallinity, microfibrillar angle, defects, and physical characteristics. To achieve the highest potential, the data dependent on these criteria are of interest. Natural fibres are known to be prone to deterioration, depending on the individual elements, such as organic, chemical, mechanical, thermal, photochemical, and aqueous (Mochane et al. 2019). For example, lignin is primarily responsible for the degradation of UV and heat, and hemicellulose is responsible for biological and thermal degradation, and high absorption of moisture in fibres (Azwa et al. 2013; Marques et al. 2014). One of the main limitations preventing their technical implementations was an inherited hydrophilic character (Gurunathan et al. 2015; Neher et al. 2016). This results in poor interfacial interaction with polymeric hydrophobic materials that limit the transfer of stress between the composite components (Gupta 2017). However, the handling of natural fibres, when exposed to various conditions, may increase their biodegradation stability (Azwa et al. 2013).
Several variables are dependent on the mechanical properties of hybrid polymer composites. These considerations are the dispersion and distribution of the reinforcements in the polymer matrix selected, the interfacial adhesion between the polymer and the reinforcements, the large surface area, the high aspect ratio of the reinforcements, the mechanical properties of the reinforcements, the loading effect, the adjustment of the surface, the dimension of the fibre and the orientation of the natural fibres (Bisaria et al. 2015). Mechanical properties are commonly documented as a function of loading, duration, and fibre treatment in many experiments (Gupta and Srivastava 2015; Kureemun et al. 2018; Shanmugam and Thiruchitrambalam 2013). Several studies have been published on the development of hybrid polymer composites from both thermosets and thermoplastics using synthetic and natural fibres as well as the combination of nanomaterial fibres and their elucidated mechanical and thermomechanical properties (Akil et al. 2014; Ramana and Ramprasad 2017; Safri et al. 2017).

The need for the use of more than one type of reinforcement is that one type's benefit will complement another's drawback, thus enhancing the properties and efficiency of the resulting material. Besides, demand for the production of such materials is growing as they fulfil the requirements of many goods, such as door panels and car interiors in transport vehicles (Kureemun et al. 2018). The prediction of the mechanical behaviour of hybrid materials depends on the parameters of the material, such as mechanical characteristics of the reinforcement (fibres or particles), mechanical characteristics of the matrix, reinforcement distribution and dispersion, reinforcement volume fractions, and test conditions (Mochane et al. 2019).

In domestic homes, transportation, aerospace, and military applications, there is great demand for fire retardant (FR) products (Boulos et al. 2013). Improving the fire retardation of polymeric materials is a priority and a big challenge too. Appropriate use of FR materials and fire safety devices will greatly reduce the human and economic cost of fire. Developing thermomechanical models that predict accurately the response of a fire-exposed reinforced fibre-polymer composite is critical for engineers in determining the integrity of structural members (Brown and Mathys 1997). Certainly, composites are widely used in aerospace, marine, infrastructure, and chemical processing applications so there is potential for fire events occurring in each of these applications (Eggleston and Turley 1994; Scudamore 1994).

The degradation of the composite material's structural integrity as a result of exposure to fire is a significant safety issue and this decomposition of composite material along with the spread of flames and the release 
of heat, smoke and toxic fumes is of major concern for safety measures (Tewarson, and Macaione 1993). Invariably, a large amount of research has been done to study the fire reaction behaviour of structural composite materials, and there is plenty of information available regarding their fire reaction properties such as heat release rate, time to ignition, flame spread, gas emissions, smoke density and smoke toxicity (Raju et al. 2012). A loss of stiffness, strength, or creep resistance, however, can cause deformation and the ultimate collapse of a composite structure that could result in injury and death (Ezeh et al. 2020). Therefore, it is not surprising that natural fibre composites have found numerous applications in the engineering industry. This helped to contrive this research work aimed at developing a bio-flame retardant material to improve the thermal properties of polyesterbanana peduncle fibre composite using cow horn particles, which is cost-effective and environmentally friendly.

\section{Methods}

\section{Banana peduncle fibre}

Banana peduncle fibre is the reinforcing material. It was obtained at no charge from banana sellers on the Ogbete Main market in Enugu state Nigeria. For 25 days, the banana peduncle underwent a water retting process to remove the fibres from the peduncle. At the internode, the peduncle was chopped and gently beaten to loosen and separate the fibre with a mallet in another. Water retting increased the output of fibres that were more similar and of high quality. The fibres were cut, hand-robbed and rinsed inadequate water from the water retting tank. The resulting bundle of fibres was scrapped and combed with a knife. The combing and scrapping process was repeated until it separated individual fibres. The separated fibres were carefully washed with running tap water to remove any impurities. Finally, for one week in ambient air, the banana peduncle fibre was sun-dried to extract the full moisture from the fibre for further chemical treatment and examination (Fig. 1A and B).

\section{Cow horn ash particles}

The fire retardant filler material cow horn used for this research, was sourced from the Artisan Market Abattoir in Enugu, Nigeria State of Enugu. The cow horn was washed with water for four weeks, and sun-dried. The horn was manually compressed with a hammer, and the bony centre was removed from the keratin sheath. Around $5 \mathrm{~kg}$ was washed with water and degreased by soaking it in $5 \mathrm{~L}$ of acetone for two hours, to eliminate any bone blood and other substances that would prevent proper matrix bonding with the additive. The degreased bony core was then 2 weeks sundried (Fig. 2A). Eventually, in the absence of oxygen, the bony core was carbonized in a muffle furnace at a temperature of $1200{ }^{\circ} \mathrm{C}$ (Fig. 2B).

The carbonized bonny core was size reduced using a hammer mill and sieved to a particle size of $125 \mu \mathrm{m}$. The choice of this particle size was informed from literature which gave a range of $(90-355 \mu \mathrm{m})$ for particles as having the best tendency to enhance surface activity and blending with a polymer-coupling agent (Louis and Ross 2017). Generally increasing particle size improves the mechanical properties of particulate reinforced polymer composites. Tensile and flexural properties also are found to gradually increase with increasing particle size (Sreekala et al. 2012).

\section{Composite formulation}

In the proposed composite composition, a foundation of $302.40 \mathrm{~g}$ total mass was used. This was derived from the polyester density and volume of the fabrication mould.

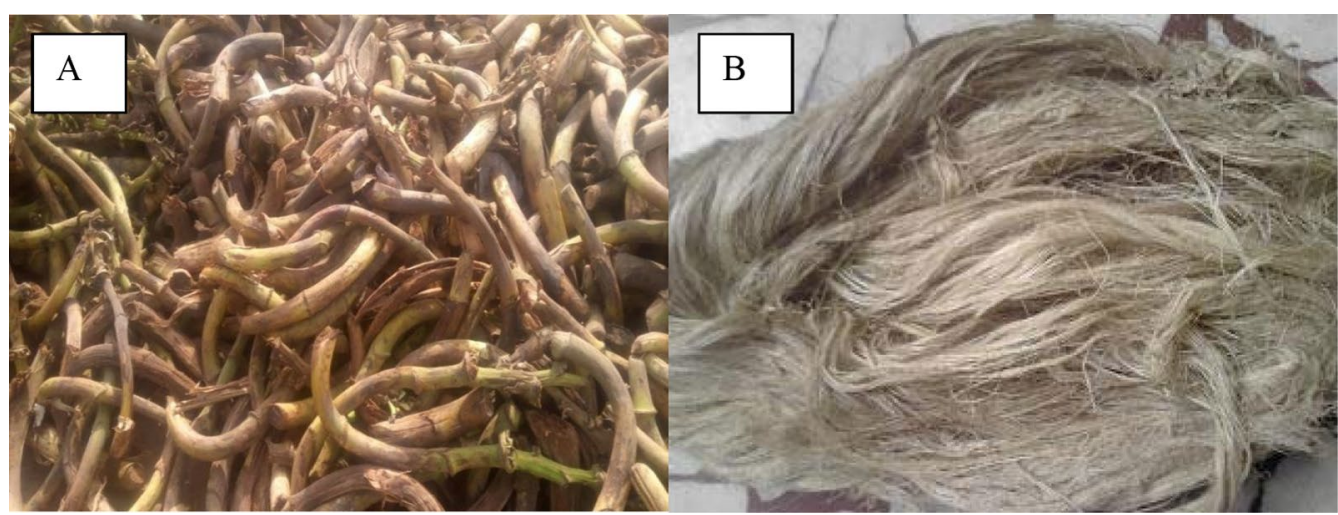

Fig. 1 A Banana peduncles. B Banana peduncle fibre after extraction (Ezeh et al. 2020) 


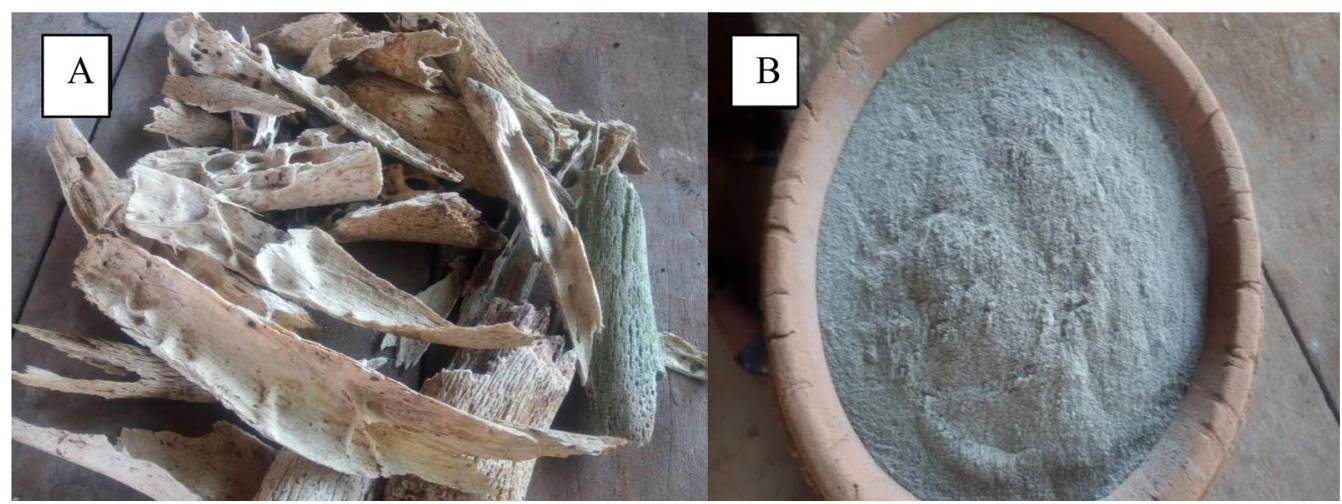

Fig. 2 A Photograph of cow horn bony core, B the sieved cow horn (bone) (Ezeh et al. 2020)

Table 1 Compositions of composites samples

\begin{tabular}{llll}
\hline Sample & CHAp $(\% w / w)$ & BPF $(\% w / w)$ & P (\%w/w) \\
\hline 1 & 0 & 0 & 100 \\
2 & 2.5 & 2.5 & 95 \\
3 & 5 & 5 & 90 \\
4 & 7.5 & 7.5 & 85 \\
5 & 10 & 10 & 80 \\
\hline
\end{tabular}

BPF Banana peduncle fibre, CHAP cow horn ash particle, $P$ polyester resin

\section{Cone calorimetric analysis}

For this analysis of the fire properties of the studied composites, the cone calorimeter instrument was used. Test samples developed from the formulated composites (Table 1) were cut to dimensions of $100 \times 100 \mathrm{~mm}$ on a table saw. All materials are rated at $23 \pm 30 \mathrm{C}$ and $50 \pm 5 \%$ relative humidity $24 \mathrm{~h}$ before testing. Upon putting the samples in the holder and then in the cone calorimeter, the samples were lined with aluminium foil around the back and sides. It was done to prevent any molten material from leaking from the sample to the charging container. The samples were then backed up with noncombustible refractory material (brick) for insulation. After ASTM E1354 all tests were carried out. All the tests were performed on the cone calorimeter assembled by limited fire testing technology. The samples were horizontally oriented and exposed to $50 \mathrm{~kW} / \mathrm{m}^{2}$ irradiances at a temperature of $600{ }^{\circ} \mathrm{C}$ (Fig. 3). The samples were pilot ignited and ran in triplicate; the average score of every three runs for a sample was taken as experimental value.

\section{Thermogravimetric analysis (TGA)}

Thermal decomposition (TGA) of the samples was observed in terms of global mass loss using a TGA Instrument (TGA Q50 thermogravimetric analyser). The

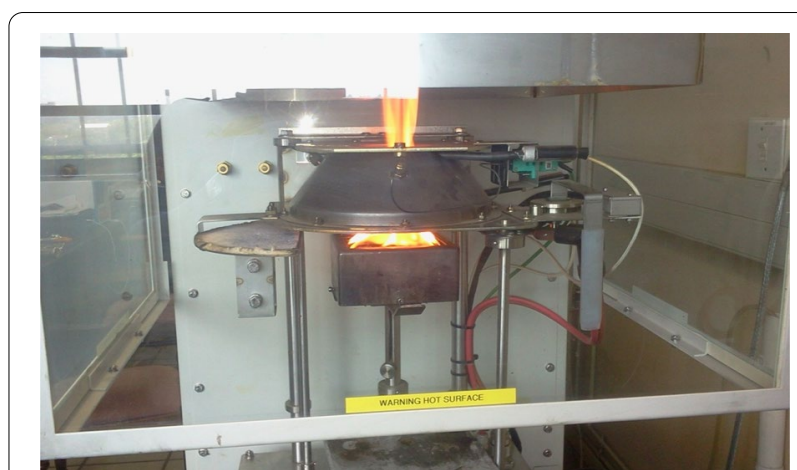

Fig. 3 Photograph of sample flaming inside the cone

apparatus detects the mass loss with a resolution of 0.1 as a function of temperature. The samples were evenly and loosely distributed in an open sample pan of $6.4 \mathrm{~mm}$ diameter and $3.2 \mathrm{~mm}$ deep with an initial sample weight of 8-10 mg. The temperature change was controlled from room temperature $\left(25 \pm 3{ }^{\circ} \mathrm{C}\right)$ to $1000{ }^{\circ} \mathrm{C}$ with a heating rate of $10{ }^{\circ} \mathrm{C} / \mathrm{min}$. High purity argon was continuously passed into the furnace at a flow rate of $60 \mathrm{ml} / \mathrm{min}$ at room temperature and atmospheric pressure. Before starting each run, the argon was used to purge the furnace for $30 \mathrm{~min}$ to establish an inert environment to prevent any unwanted oxidative decomposition. The TGA and DTA curves were obtained from TGA runs using universal analysis 2000 software from TGA Instruments (Fig. 4).

\section{Results}

\section{Cone calorimeter fire property test of polyester with BPF and CHAp}

A cone calorimeter was used to obtain combustion information of CHAp, BPF and Polyester composite (Table 2). This technique investigated how materials burnt when exposed to the typical heat flux of a fire. 


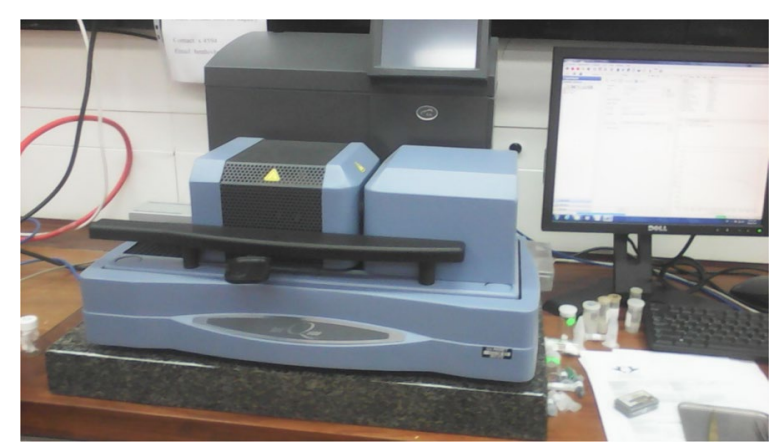

Fig. 4 Photograph of DTA-TGA equipment. (TA Instruments)

The flammability parameters evaluated include MHRR (Mean heat release rate), PHRR (Peak heat release rate), THR (Heat release rate), Total smoke production (TSP), Total smoke released (TSR), TTG (Time to ignition), TOC (Total oxygen consumed), and ETT (End of test time).

From Table 2, CHAp delayed the TTI of the composites by $25 \%$. This delay could provide valuable time to evacuated a site or extinguish a fire in the event of a fire. The HRR peak value of the composites decreased as the percentage CHAp addition increased.

The smoke generated by fire is toxic and opaque and seriously endangers personnel safety. Therefore, it is vital to detect the smoke production when materials burn. The TSP and TSR of the composites with CHAp decreased progressively as the wt\% CHAp loading increased. This indicated that $\mathrm{CHAp}$ has smoke suppression performance. The MHRR is used as an indicator to measure the tendency for fire to develop under real conditions. The MHRR of the composites decreased as CHAp addition increased. This reduction indicated that CHAp can indeed diminish the tendency for fire to develop.

\section{DTA/TGA analysis of CHAp and BPF}

The temperature of destruction (Tdes) of CHAp and BPF was determined from the DTA curves. DTA data were recorded on "Derivatograph OD 102", (Q50 thermogravimetric analyser) at a heating rate of $10{ }^{\circ} \mathrm{C} / \mathrm{min}$ in argon. The results of the DTA/TGA scan of CHAp and BPF are shown in Figs. 5 and 6. TGA curve of CHAp indicated that it exhibited less decomposition potential. At

Table 2 Fire properties of developed composites of polyester with BPF and CHAp

\begin{tabular}{|c|c|c|c|c|c|c|c|c|c|}
\hline Samples & $\operatorname{MHRR}\left(\mathrm{KW} / \mathrm{m}^{2}\right)$ & PHRR $\left(\mathrm{KW} / \mathrm{m}^{2}\right)$ & THR $\left(\mathrm{MJ} / \mathrm{m}^{2}\right)$ & MASS loss $\left(\mathrm{g} / \mathrm{m}^{2}\right)$ & $\operatorname{TSR}\left(\mathrm{m}^{2} / \mathrm{m}^{2}\right)$ & $\operatorname{TSP}\left(\mathrm{m}^{2}\right)$ & TOC $(g)$ & TTG (s) & $\operatorname{ETT}(s)$ \\
\hline Polyester & 223.56 & 556.54 & 308.60 & $14,142.10$ & 9378.20 & 82.90 & 206.30 & 64.00 & 1445.00 \\
\hline 2.5\%BPF:2.5\%CHAp & 223.47 & 534.19 & 308.20 & $13,843.10$ & 8889.20 & 81.40 & 203.90 & 65.00 & 1540.00 \\
\hline 5\%BPF:5\%CHAp & 222.39 & 516.23 & 301.20 & $13,754.50$ & 8579.40 & 80.60 & 200.10 & 75.00 & 1585.00 \\
\hline 7.5\%BPF:7.5\%CHAp & 206.84 & 501.80 & 280.90 & $13,106.00$ & 8161.50 & 78.90 & 129.32 & 80.00 & 1685.00 \\
\hline 10\%BPF:10\%CHAp & 207.57 & 505.42 & 207.90 & $12,580.20$ & $80,582.00$ & 70.90 & 121.16 & 82.00 & 1705.00 \\
\hline
\end{tabular}

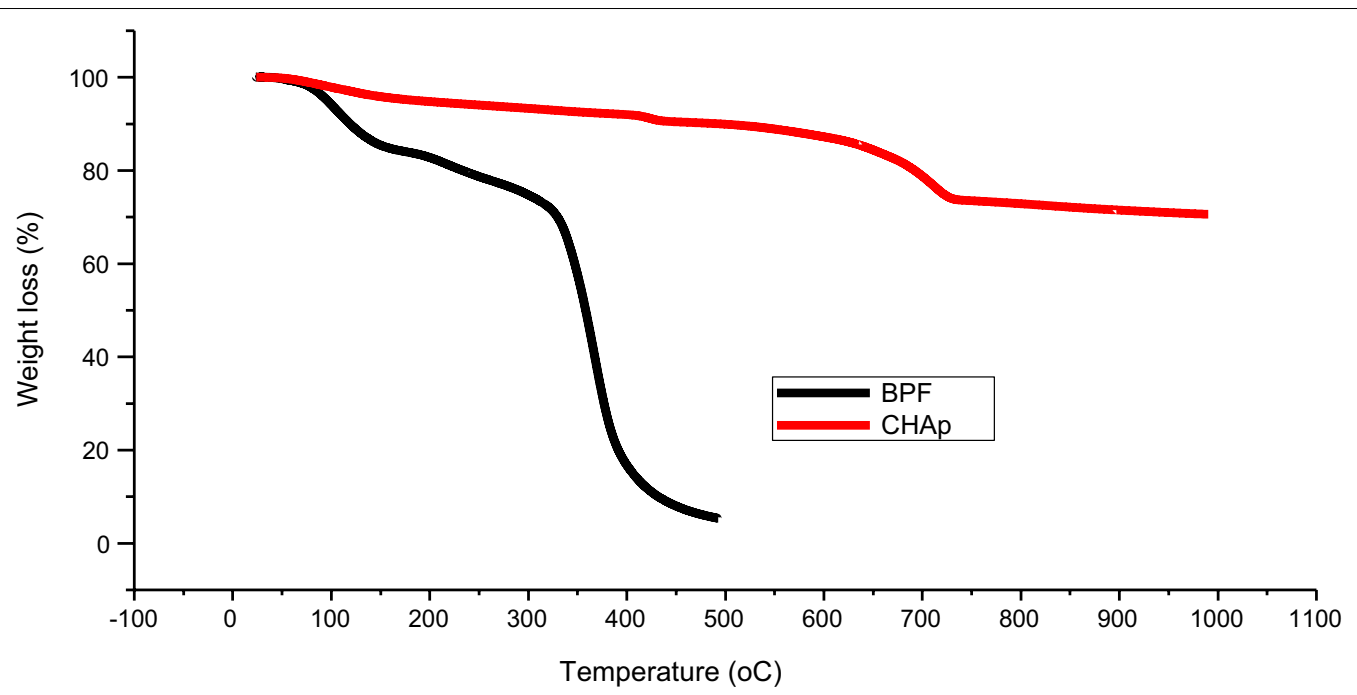

Fig. 5 TGA curves of the CHAp and BPF 


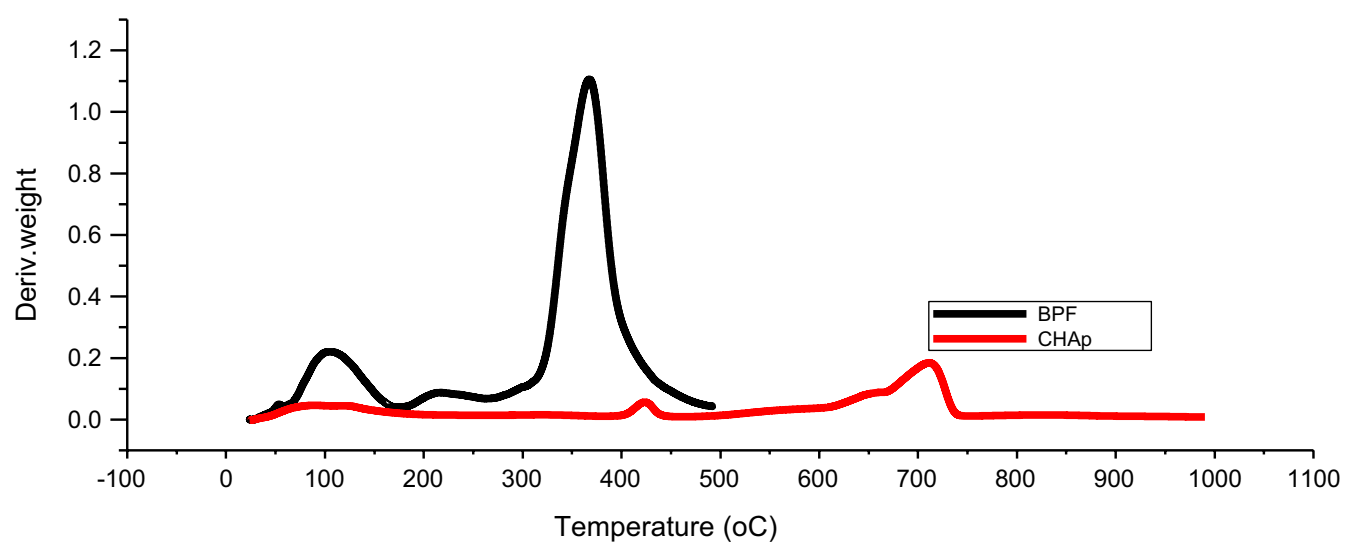

Fig. 6 DTA curves of the CHAp and BPF

temperatures above $700{ }^{\circ} \mathrm{C}$, the residual weight of CHAp stabilized as a result of the silica and $\mathrm{CaO}$ contents. This was in agreement with the values earlier reported in the literature (Ezeh et al. 2019). As the sample was heated up to $700{ }^{\circ} \mathrm{C}$, it started to decompose and decomposition byproducts including silica and calcium oxide were formed. The silica and calcium oxide delayed the degradation process and made CHAp more thermally stable when compared to BPF. From the thermal analysis results, CHAp retained $80 \%$ of its weight at a temperature of $1000{ }^{\circ} \mathrm{C}$ (Fig. 5).

From Fig. 5, the thermal decomposition of BPF showed an onset decomposition temperature (Tdes) at $200{ }^{\circ} \mathrm{C}$, and the thermal decomposition process had only one stage with Tmax at $350{ }^{\circ} \mathrm{C}$ (Fig. 6). BPF left almost no char (residue) at a temperature of $495{ }^{\circ} \mathrm{C}$. The higher temperature of thermal stability of CHAp than BPF indicated that $\mathrm{CHAp}$ can serve as a flame retardant additive which could be used to increase the thermal stability of composites.

\section{Degradation temperatures of composites determined using DTA/TGA}

The thermal decomposition of the polyester and its composites were examined by thermogravimetric analysis
(TA) in an inert (nitrogen) atmosphere. Nitrogen was used as the atmospheric gas in the TA rather than air or oxygen because (except for the near-surface region) the endothermic decomposition reaction of the organic constituents occurs with little or no oxygen present (Tables 3 , 4 and 5).

Figures 7, 8 and 9 display the TGA curves of the composites. The decomposition of the materials was characterized by multiple-stage reactions. A small loss in mass occurred in the first stages when the sample was heated from 50 to $150{ }^{\circ} \mathrm{C}$ and this was due to the loss of moisture absorbed from the atmosphere and the water formed as a by-product of the cure reaction. The TGA curve remained relatively flat until the main decomposition reaction occurred over a temperature range of $350-420^{\circ} \mathrm{C}$.

It was observed in Fig. 7 that the TGA curves of composites produced with CHAp had a higher weight retained (residue) than in Fig. 8, showing the curve of the composites produced with BPF. Also, it was noticed that as the weight percentage of CHAp increased, the weight of residue left increased. In the composites produced with BPF, as the weight percentage increased, there was a decrease in the weight of residues left, (Tables 3 and 4), respectively.

Table 3 Degradation temperatures of composites with BPF

\begin{tabular}{lllllll}
\hline Composites & $\mathbf{T}_{\mathbf{1 0} \%}$ weight loss & $\mathbf{T}_{\mathbf{5 0 \%}}$ weight loss & $\mathbf{T}_{\mathbf{8 0} \%}$ weight loss & $\mathbf{T}_{\max }$ & $\mathbf{T}_{\text {final }}$ weight loss & $\begin{array}{l}\text { Residues } \\
\text { weight (\%) }\end{array}$ \\
\hline 0\%BPF & 260.64 & 372.48 & 398.54 & 402.00 & 593.57 & 5.28 \\
$5 \% \mathrm{BPF}$ & 253.65 & 363.40 & 391.92 & 400.00 & 593.95 & 4.94 \\
$10 \% \mathrm{BPF}$ & 252.81 & 362.58 & 395.86 & 394.00 & 594.00 & 4.49 \\
$15 \% \mathrm{BPF}$ & 250.12 & 361.01 & 391.01 & 395.00 & 593.99 & 2.82 \\
20\%BPF & 239.13 & 360.36 & 390.82 & 392.30 & 593.73 & 1.359 \\
\hline
\end{tabular}


Table 4 Degradation temperatures of composites with CHAp

\begin{tabular}{|c|c|c|c|c|c|c|}
\hline $0 \%$ CHAp & 260.84 & 372.48 & 398.40 & 405.80 & 593.57 & 5.28 \\
\hline $5 \%$ CHAp & 260.84 & 372.40 & 398.54 & 407.30 & 593.57 & 5.28 \\
\hline $10 \%$ CHAp & 265.38 & 375.39 & 398.06 & 408.00 & 594.09 & 8.47 \\
\hline $15 \%$ CHAp & 265.79 & 379.99 & 403.06 & 412.00 & 594.34 & 11.64 \\
\hline $20 \%$ CHAp & 370.81 & 380.99 & 428.26 & 415.00 & 593.96 & 17.67 \\
\hline
\end{tabular}

Table 5 Degradation temperatures of composites with CHAp and BPF

\begin{tabular}{|c|c|c|c|c|c|c|}
\hline 0\%CHAp: 0\%BPF & 260.84 & 372.48 & 398.40 & 402.00 & 593.57 & 5.28 \\
\hline 2.5\%CHAp: $2.5 \%$ BPF & 267.08 & 376.49 & 400.76 & 402.00 & 593.94 & 9.55 \\
\hline 5\%CHAp: 5\%BPF & 309.99 & 384.03 & 407.15 & 404.60 & 593.46 & 9.63 \\
\hline 7.5\%CHAp: $7.5 \%$ BPF & 347.10 & 385.85 & 409.15 & 407.00 & 593.04 & 9.81 \\
\hline 10\%CHAp: 10\%BPF & 348.64 & 382.49 & 418.19 & 407.15 & 593.75 & 10.39 \\
\hline
\end{tabular}

The introduction of CHAp particles into the polyester induced a protective barrier against thermal decomposition and retarded the thermal decomposition of polyester/CHAp composite. This phenomenon could be attributed to the physical barrier effect of the incorporated microparticles of CHAp acting as the mass and heat transfer barriers. This result inferred that the thermal stability of polyester/BPF composite could be improved with the addition of CHAp microparticles.

Figure 9 shows the decomposition characteristics of the hybrid composites of polyester-CHAp/BPF with temperature. It was observed that as the weight of CHAp increased in the formulation, there was a rise in the thermal stability of the composites. About $20 \%$ weight char or residue remained when $7.5 \mathrm{wt} \%$ CHAp was added to the composite. The increase in the thermal stability of the composites could be attributed to the fact that $\mathrm{CHAp}$ retarded the decomposition of the composites.

\section{Fire property optimization}

The composite's thermal behaviour was studied using a cone calorimeter and analysed for different weights per cents of composite materials (5, 10 and $15 \mathrm{wt} \%$ ). Times of $200 \mathrm{~s}, 600 \mathrm{~s}$ and $1000 \mathrm{~s}$ were used as lower, middle, and upper rates, to optimize the total heat release rate for the smaller the better. The key factors (controlling factors) affecting the overall heat release rate are as follows: (A) reinforcement type, (B) time, and (C) the weight per cent of reinforcement material (Table 6).

The experimental design orthogonal matrix L9 (Table 7) was obtained through the application of the Taguchi mixed-level design. The orthogonal matrix was developed using the statistic tool Minitab 18.
There are generally three types of $\mathrm{S} / \mathrm{N}$ ratio: 'smaller is better,' 'larger is better 'and' normal is better' which are used for quality measurement (Stojanovic et al. 2019). For analysis of the total heat release rate in this work, characteristics $\mathrm{S} / \mathrm{N}$ ratio "smaller is better" has been implemented. The equation for calculating the "smaller is better" S/N ratio for Taguchi characteristics is calculated via the equation (Stojanovic et al. 2019).

$$
\frac{S}{N}=-10 \log \frac{1}{n}\left(\sum y^{2}\right)
$$

where $\mathrm{S} / \mathrm{N}$ is the signal-to-noise ratio, $\mathrm{n}$ is the number of repetitions for each test and yi is the product of $\mathrm{i}$-experiment for each test.

Based on the $\mathrm{S} / \mathrm{N}$ analysis the $\mathrm{S} / \mathrm{N}$ ratio is calculated for each level of influencing parameters. The statistical variable analysis is used to consider the statistical value of parameters. One can estimate the optimum combination of parameters. Experimental values for the total heat release rate have been obtained by using an orthogonal array for various combinations of factors and are given in Table 7. The $\mathrm{S} / \mathrm{N}$ ratio values for heat release rate are also shown in Table 7.

\section{Discussions}

$\mathrm{S} / \mathrm{N}$ trial analysis

In Table 7, the effect of control parameters on the mean heat release rate is shown. Based on the rating, it is observed that the time value is the most influential parameter affecting the heat release rate, followed by the reinforcement form of weight per cent. The form of reinforcement exerted the least effect on the rate of heat release. 


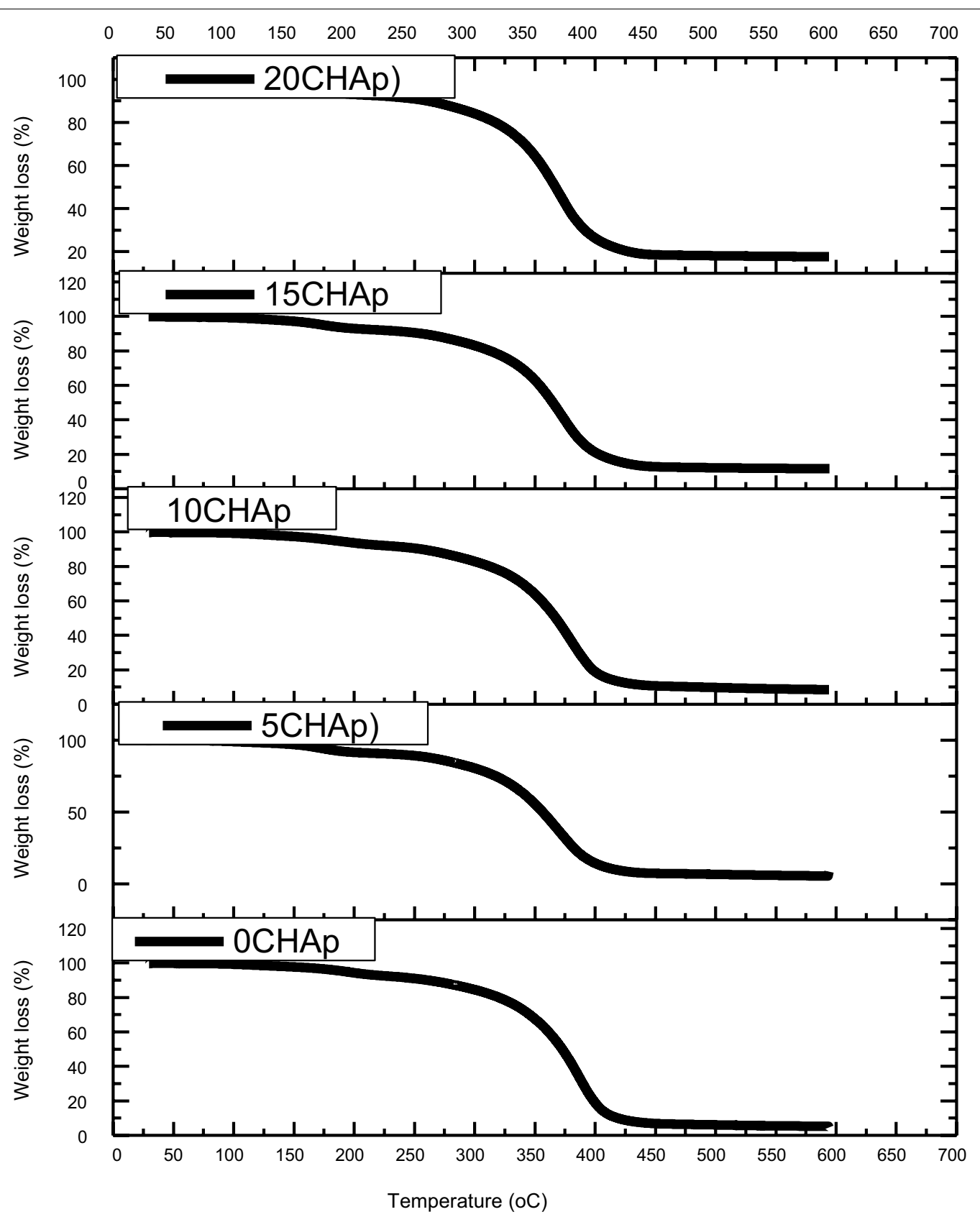

Fig. 7 Variation of percentage weight loss with temperature for composite produced with CHAp

Figure 10 provides a graph of the significant effects of the impact on the heat release rate of the different test parameters. Unless the line for a specific parameter is near horizontal in the main effect diagram, then the parameter does not have any noticeable effect. In contrast, the most significant effect will be a parameter for which the line has the highest inclination. In this case, the time has the greatest influence on the rate of heat release followed by weight per cent of the type of reinforcement, while the type of reinforcement has the least influence on the rate of total heat release.

Figure 11 shows the interactions between certain parameters on the total heat release rate and their reciprocal effect. 


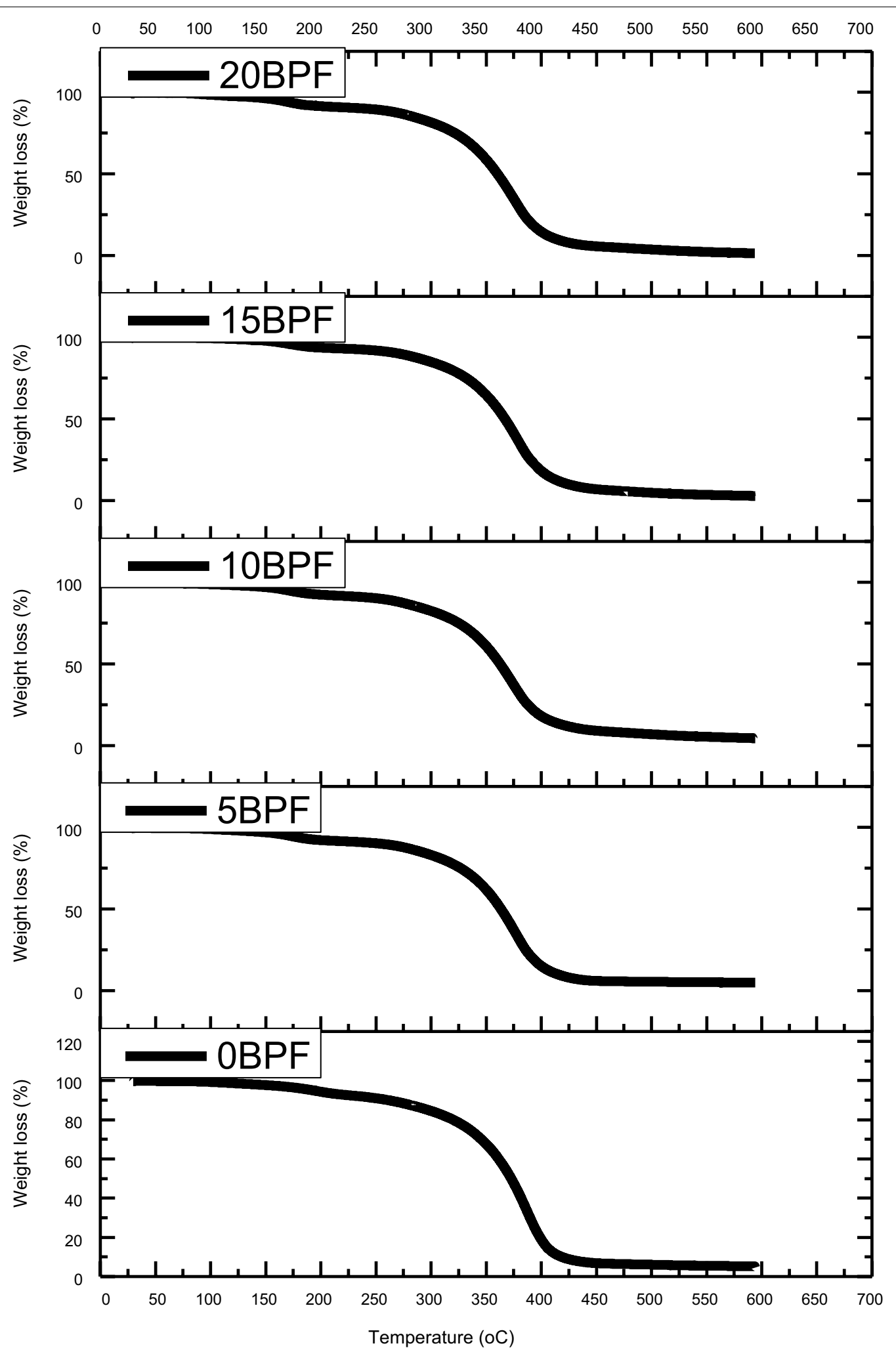

Fig. 8 Variation of percentage weight loss with temperature for composites Produced with BPF 


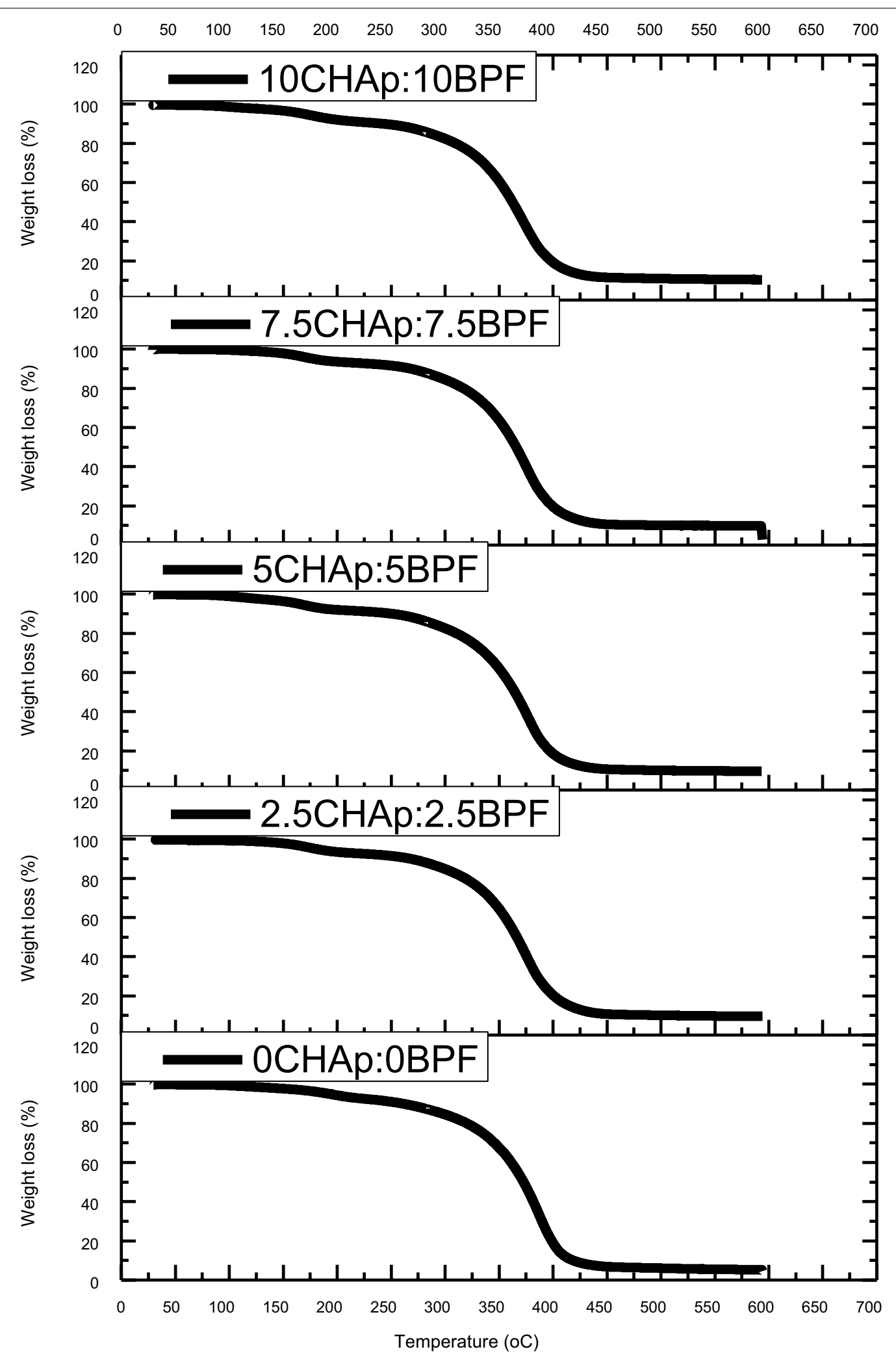

Fig. 9 Variation of percentage weight loss with temperature for composite produced with CHAp and BPF 
Table 6 Levels of various control factors

\begin{tabular}{lllll}
\hline Control factors & Units & Level I & Level II & Level III \\
\hline A. Reinforcement type & $\%$ & CHAp/P & CHAp/BPF/P & BPF/P \\
B. Time & S & 200 & 600 & 1000 \\
$\begin{array}{l}\text { C. Wt\% of reinforcement } \\
\text { material }\end{array}$ & Wt $\%$ & 5 & 10 & 15 \\
\hline
\end{tabular}

CHAp Cow horn ash particle, BPF banana peduncle fibre, $P$ Polyester

Table 7 Experimental design using L9 orthogonal array

\begin{tabular}{llllrl}
\hline S/NO & $\begin{array}{l}\text { Reinforcement } \\
\text { type }\end{array}$ & Time (s) & $\mathbf{W t} \%$ & $\mathrm{THR}\left(\mathrm{MJ} / \mathbf{m}^{2}\right)$ & $\mathbf{S} / \mathrm{N}$ ratio \\
\hline 1 & 1 & 1 & 1 & 31.94 & -30.0867 \\
2 & 1 & 2 & 2 & 140.36 & -42.9449 \\
3 & 1 & 3 & 3 & 295.52 & -49.4117 \\
4 & 2 & 1 & 2 & 40.05 & -32.0521 \\
5 & 2 & 2 & 3 & 128.07 & -42.1489 \\
6 & 2 & 3 & 1 & 325.30 & -50.2457 \\
7 & 3 & 1 & 3 & 33.12 & -30.4018 \\
8 & 3 & 2 & 1 & 159.31 & -44.0449 \\
9 & 3 & 3 & 2 & 309.00 & -49.7992 \\
\hline
\end{tabular}

Reinforcement type: $1=\mathrm{CHAp} / \mathrm{P}, 2=\mathrm{CHAp} / \mathrm{BPF} / \mathrm{P}, 3=\mathrm{BPF} / \mathrm{P}$, Time $(\mathrm{s}): 1=200$, $2=600,3=1000, \mathrm{Wt} \%: 1=5$ or $2.5: 2.5,2=10$ or $5: 5,3=15$ or $7.5: 7.5$

\section{Analysis of variance results for the total heat release rate} The study findings were analysed using an analysis of variance (ANOVA). This method was used to test the effect of the parameters considered on the total heat release rate (reinforcement type, time, and weight percentage of the type of reinforcement). The independent factor dominates over the other, and the contribution percentage of that particular independent variable was calculated by performing variance analysis.

The findings of ANOVA for the total heat release rate for three factors and interactions of those factors are shown in Table 8. This study was performed at a significant level of $\alpha=0.05$, that is at a $95 \%$ confidence interval. Parameters with a $P$ value of less than 0.05 were considered to contribute statistically significantly to the performance measures. The last column in Table 8 shows the percentage contribution (Pr) of each parameter on the total variation showing its degree of influence on the outcome.

Time has the largest effect on the overall heat release rate $(81.72 \%)$ from Table 5 . The type of reinforcement wt\% (10.37\%) and form of reinforcement (5.28\%) have a lesser impact on the heat release rate. The biggest influence is due to time $(0.84 \%)$ as regards interactions. Other interactions had smaller impacts.

Figures 12, 13, 14 and 15 show 2D and 3D interface diagrams of the total heat release rate and the parameters influencing it.

\section{Multiple regression models}

Multiple linear regression models were developed using "MINITAB 18" Statistical Software. This model by setting a linear equation for the observed data gives the ratio between parameters and response. The regression

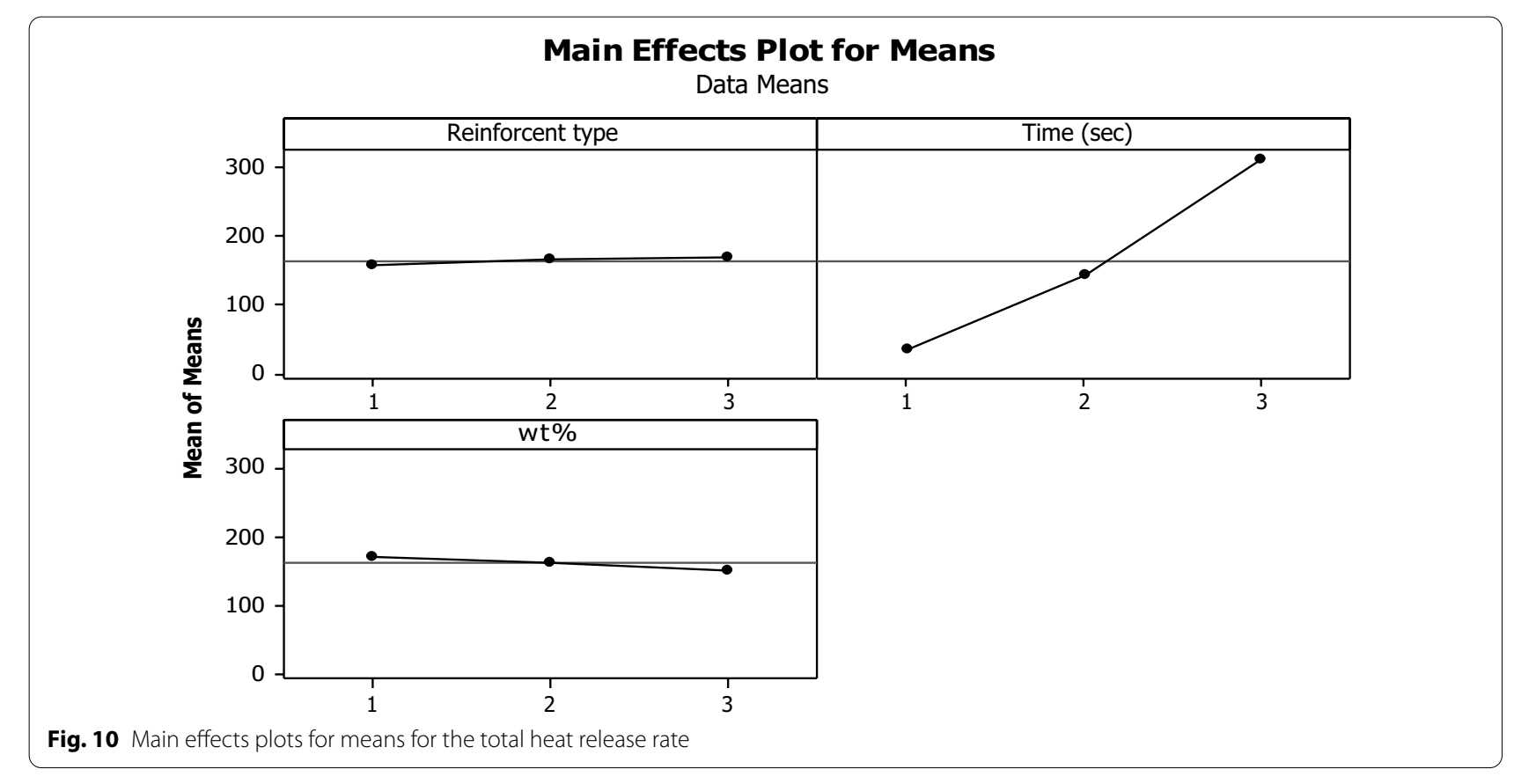




\section{Main Effects Plot for $\mathbf{S} / \mathbf{N}$ ratios}

Data Means

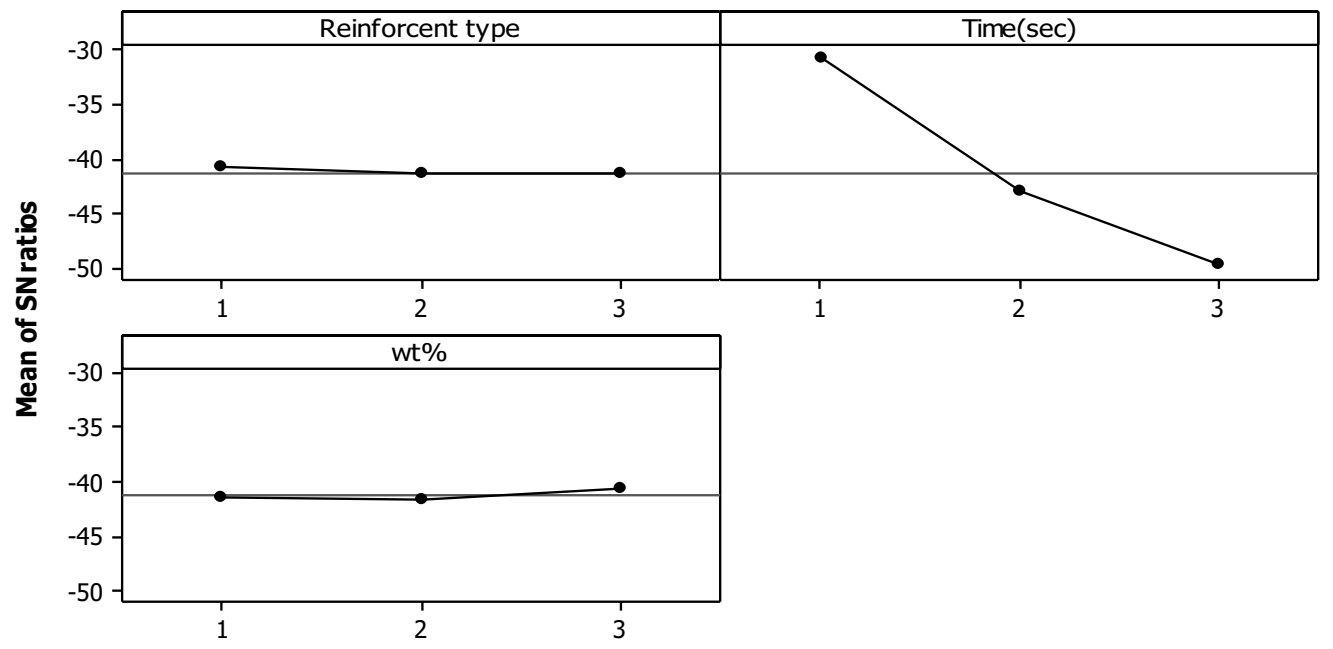

Signal-to-noise: Smaller is better

Fig. 11 Interaction plot for means and the total heat release rate

Table 8 Analysis of variance of $\mathrm{S} / \mathrm{N}$ ratios for the total heat release rate

\begin{tabular}{|c|c|c|c|c|c|c|c|}
\hline Source & $d F$ & Seq SS & Adj SS & Adj MS & $F$ & $\mathbf{P}$ & $\operatorname{Pr}(\%)$ \\
\hline $\mathrm{Wt} \%$ & 1 & 21.6790 & 21.6790 & 21.6793 & 318.92 & 0.000 & 10.370 \\
\hline Rt & 2 & 10.7220 & 10.6220 & 5.36120 & 73.350 & 0.001 & 5.2800 \\
\hline Time (s) & 2 & 168.659 & 168.659 & 84.7293 & 1181.11 & 0.000 & 81.720 \\
\hline Rt: time (s) & 2 & 1.57100 & 1.57100 & 0.78130 & 10.8610 & 0.025 & 0.8510 \\
\hline Rt: wt\% & 2 & 0.89400 & 0.89400 & 0.44200 & 6.1600 & 0.070 & 0.6500 \\
\hline Time (s): wt\% & 4 & 1.72400 & 1.72400 & 0.43840 & 5.9700 & 0.0570 & 0.8400 \\
\hline Residual error & 4 & 0.28800 & 0.28800 & 0.07190 & & & 0.2900 \\
\hline Total & 17 & 205.537 & & & & & 100.00 \\
\hline
\end{tabular}

equation developed in this way establishes the relation between significant parameters obtained by the analysis of ANOVA, i.e. type of reinforcement, type of reinforcement wt. per cent, and time. The regression equation of the total heat release rate formed for the $\mathrm{S} / \mathrm{N}$ ratio is as follows:

$$
\begin{aligned}
\operatorname{THR}\left(\frac{\mathrm{MJ}}{\mathrm{m}^{2}}\right)= & 103.641+5.6 R t \\
& +137.452 T(\mathrm{~s})-9.9725 w t(\%)
\end{aligned}
$$

Following the above equation, the overall heat release rate varies directly with time and type of reinforcement material and inversely with weight per cent rise in fire retardant filler material.

\section{Conclusions}

The following conclusions have been drawn, based on this analysis; the parameter design of the Taguchi method provides an organized and effectual methodology for the optimization of fire retardant properties of natural fibre-reinforced composites. ANOVA indicates that time has the greatest effect on the average heat release rate $(81.72 \%)$. The type of reinforcement weight per cent $(11.07 \%)$ and form of reinforcement $(5.07 \%)$ 


\section{Surface Plot of THR(MJ/m2) vs Reinforcent type, Time(sec)}

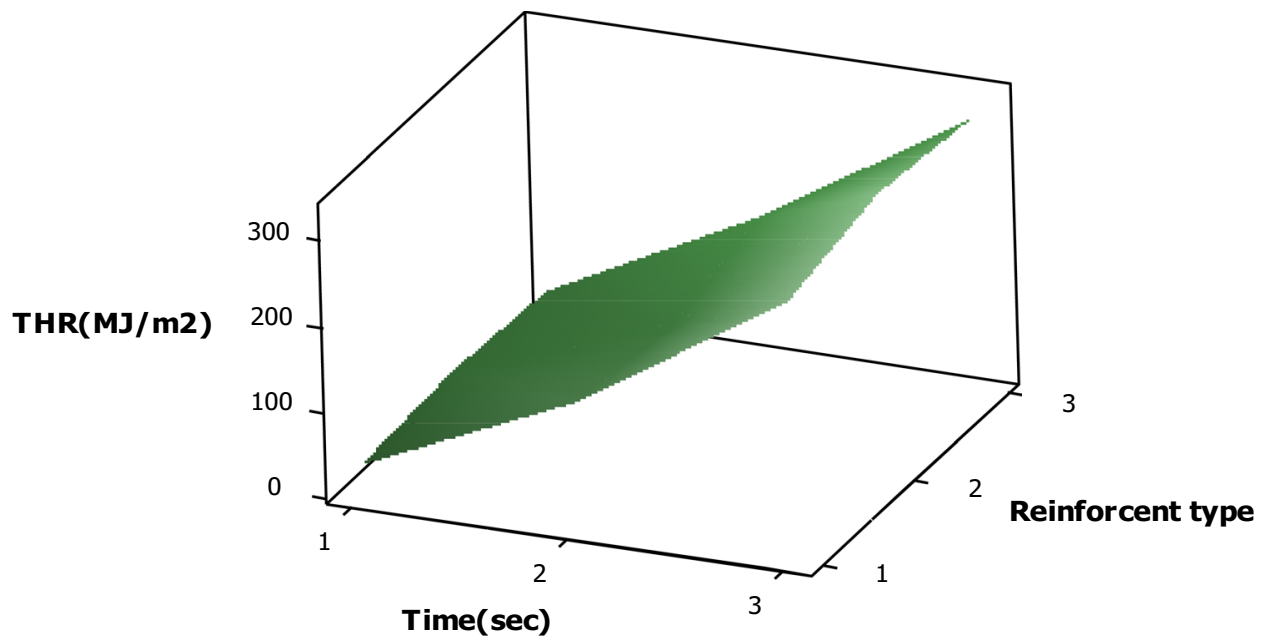

Fig. $123 \mathrm{D}$ plot of THR, reinforcement type and time

\section{Surface Plot of THR(MJ/m2) vs Reinforcent type, wt\%}

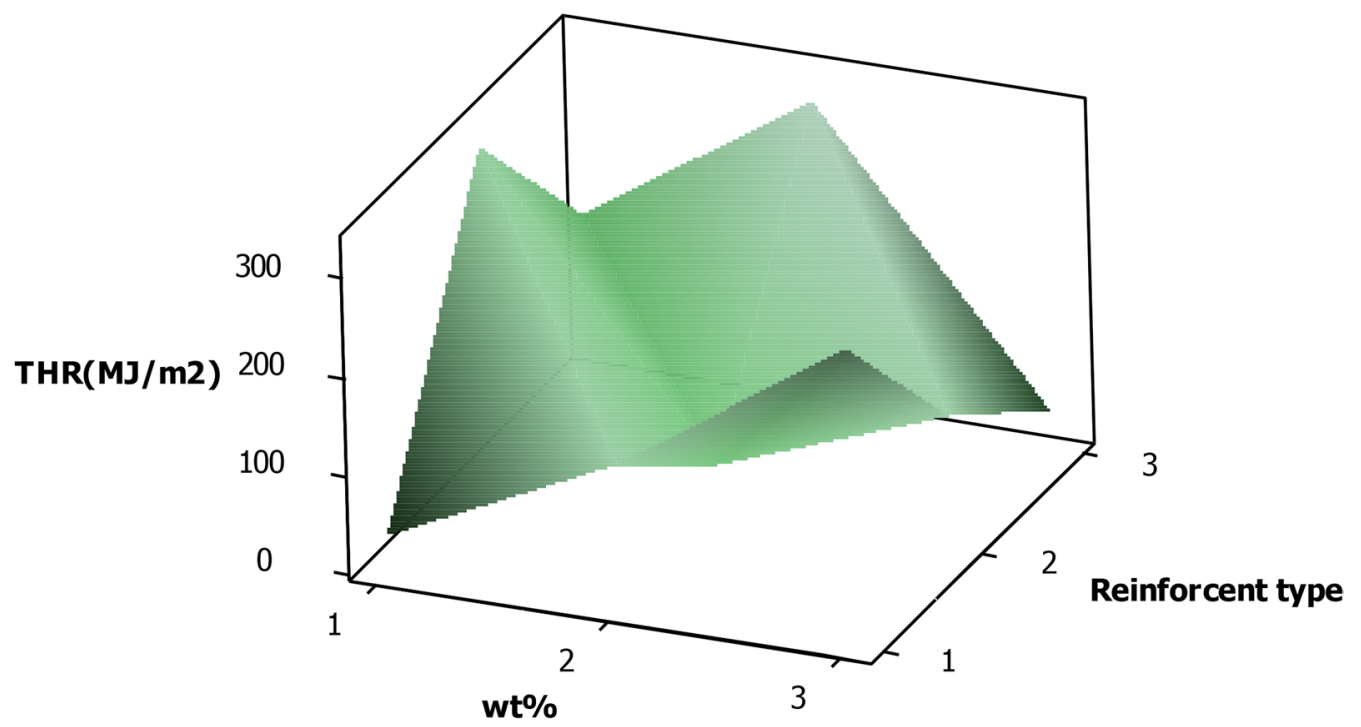

Fig. 13 3D plot of THR, reinforcement type and weight\%

have a lesser impact on the heat release rate. The approximate $\mathrm{S} / \mathrm{N}$ ratio using the optimal test indicates that time has the greatest impact on the heat release rate, followed by weight per cent of the type of reinforcement, while the type of reinforcement has the least effect on the overall heat release rate. The corresponding multiple regression model for total heat release was developed using the MINITAB software, which shows that the total heat release rate increases with an increase in time and type of reinforcement and decreases with an increase in weight per cent of fire retardant reinforcement content. 

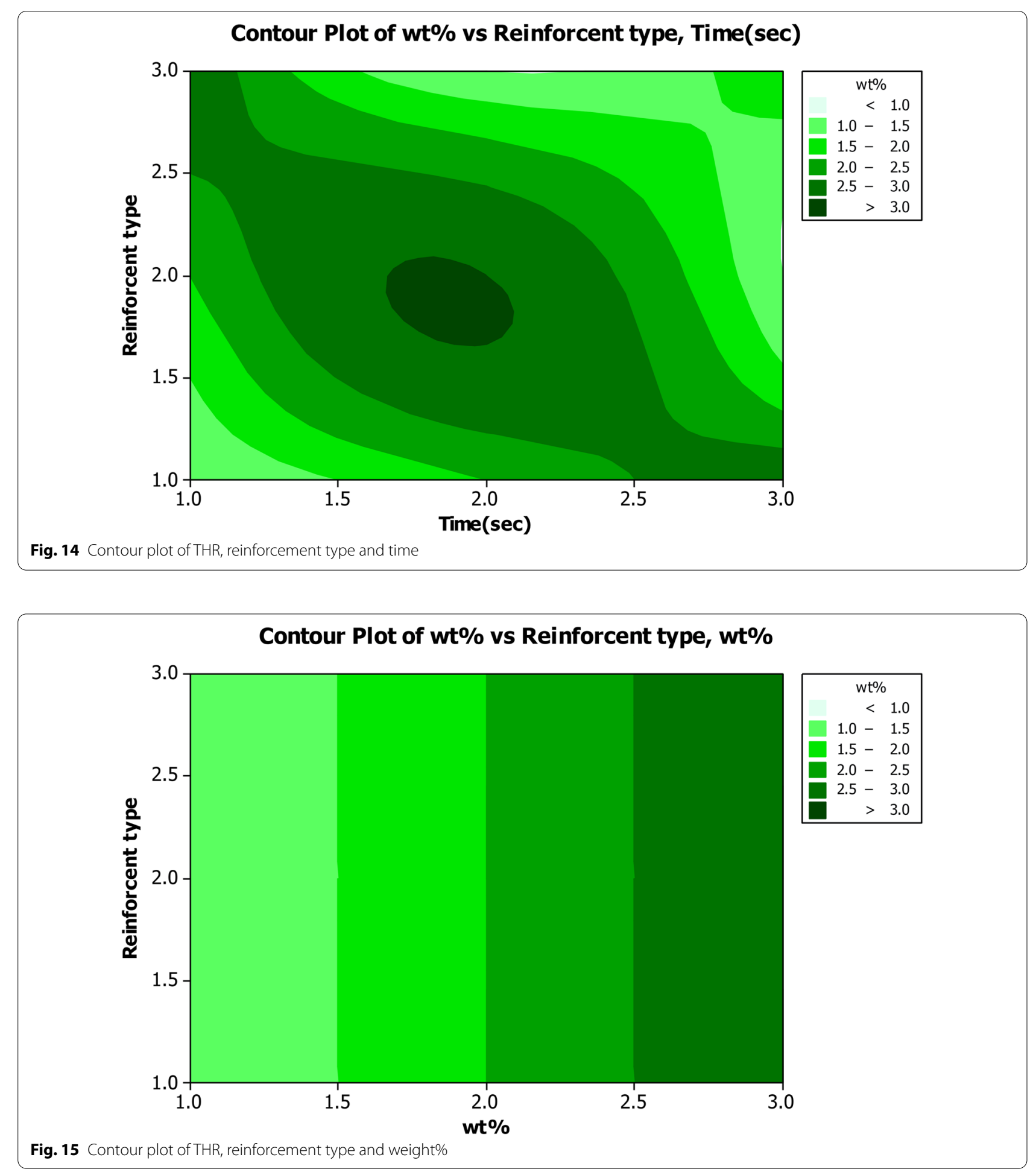

\section{Abbreviations}

MHRR: Mean heat release rate; PHRR: Peak heat release rate; THR: Heat release rate; TSP: Total smoke production; TSR: Total smoke released;TTG: Time to ignition; TOC: Total oxygen consumed; ETT: End of test time; Pr: Percentage contribution; ANOVA: Analysis of variance; S/N: Signal-to-noise ratio; CHAp:
Cow horn ash particle; BPF: Banana peduncle fibre; P: Polyester; A: Reinforcement type; B: Time; C: The weight per cent of reinforcement material; M: Mass; $\rho$ : Density; v: Volume; S: Seconds; Seq SS: Sum of squares; Adj SS: The adjusted sum of squares; Adj MS: Adjusted mean of squares; DTA: Differential thermal analysis; TGA: Thermogravimetric analysis. 


\section{Acknowledgements}

This work received administrative support from the faculty of Engineering, Nnamdi Azikwe University, Awka, Nigeria, and the Department of Chemical Engineering, Caritas University Enugu, Nigeria.

\section{Authors' contributions}

The author conceived and initiated the research work. He also sourced the literature and developed the article. The author read and approved the final manuscript.

\section{Funding}

The author received no funding for this study.

\section{Availability of data and materials}

Not applicable.

\section{Declarations}

Ethics approval and consent to participate

Not applicable.

\section{Consent for publication}

Not applicable.

\section{Competing interests}

The author declares no conflict of interest.

Received: 30 June 2021 Accepted: 4 November 2021

Published online: 18 November 2021

\section{References}

Akil HM, Santulli C, Sarasini F, Tirillo J, Valente T (2014) Environmental effects on the mechanical behaviour of pultruded jute/glass fibre-reinforced polyester hybrid composites. Compos Sci Technol 94:62-70

Azwa ZN, Yousif BF, Manalo AC, Karunasena W (2013) A review on the degradability of polymeric composites based on natural fibres. Mater Des 47:424-442

Bisaria H, Gupta MK, Shandilya P, Srivastava RK (2015) Effect of fibre length on mechanical properties of randomly oriented short jute fibre reinforced epoxy composite. Mater Today Proc 2:1193-1199

Boulos Y, Laurence L, Wassef ELK, Claude B, Bruno M (2013) New phosphonatedmethacrylates: synthesis, photocuring and study of their thermal and flame-retardant properties. Macromol Chem Phys 204:1842-1850

Brown JR, Mathys Z (1997) Reinforcement and matrix effects on the combustion properties of glass-reinforced polymer composites. Composites Part A 28A:675-681

Eggleston GT, Turley DM (1994) Flammability of GRP for use in ship superstructures. Fire Mater 18:225-260

Ezeh EM, Onukwuli OD, Odera RS (2019) Novel flame-retarded polyester composites, using cow horn ash particles. Int J Adv Manuf Technol. https:// doi.org/10.1007/s00170-019-03678-2

Ezeh EM, Onukwuli OD, Ugonabo VI, Odera RS, Okeke O (2020) Characterization of fire retardant properties of cow horn ash particles and thermal behaviour of polyester/Banana peduncle fibre/cow horn ash particle hybrid composites. J Chem Process Eng Res 62:37-46

Gupta MK (2017) Effect of frequencies on dynamic mechanical properties of hybrid jute/sisal fibre reinforced epoxy composite. Adv Mater Process Technol 3:651-664
Gupta MK, Srivastava RK (2015) Effect of sisal fibre loading on dynamic mechanical analysis and water absorption behaviour of jute fibre epoxy composite. Mater Today Proc 2:2909-2917

Gurunathan T, Mohanty S, Nayak SK (2015) A review of the recent developments in biocomposites based on natural fibres and their application perspectives. Compos A Appl Sci Manuf 77:1-25

Kureemun U, Ravandi M, Tran LQN, Teo WS, Tay TE, Lee HP (2018) Effects of hybridization and hybrid fibre dispersion on the mechanical properties of woven flax-carbon epoxy at low carbon fibre volume fractions. Compos B Eng 134:28-38

Louis R, Ross PJ (2017) Effects of methyl ethyl ketone peroxide on the performance of cast polymers. Compos Res J 1(4):14-23

Marques AR, de Oliveira PPS, dos Santos FS, Monteiro ML, de Carvalho Urashima D, de Souza RC (2014) Effects of the climatic conditions of southeastern Brazil on the degradation of the fibres of coir geotextile: evaluation of mechanical and structural properties. Geotext Geomembr 42:76-82

Mochane MJ, Mokhena TC, Mokhothu TH, Mtibe A, Sadiku ER, Ray SS, Ibrahim ID, Daramola $O O$ (2019) Recent progress on natural fibre hybrid composites for advanced applications: a review. Express Polym Lett 13(2):159-198

Mouritz AP, Gibson AG (2006) Fire properties of polymer composite materials. Solid mechanics and its applications. Springer, Berlin

Nawaz N (2011) Modelling and experimental analysis of aerospace composites in fire. A Thesis: School of Aerospace, Mechanical and Manufacturing Engineering RMIT University

Neher B, Bhuiyan MMR, Kabir H, Gafur MA, Qadir MR, Ahmed F (2016) Thermal properties of palm fibre and palm fiber-reinforced ABS composite. J Therm Anal Calorim 124:1281-1289

Raju GU, Gaitonde VN, Kumarappa S (2012) Experimental study on optimization of thermal properties of groundnut shell particle reinforced polymer composites. Int J Emerging Sci 2(3):433-454

Ramana MV, Ramprasad S (2017) Experimental investigation on jute/carbon fibre reinforced epoxy based hybrid composites. Mater Today Proc 4:8654-8664

Safri SNA, Sultan MTH, Jawaid M, Jayakrishna K (2017) Impact behaviour of hybrid composites for structural applications: a review. Compos B Eng 133:112-121

Scudamore MJ (1994) Fire performance studies on glass-reinforced plastic laminates. Fire Mater 18:313-325

Shanmugam D, Thiruchitrambalam M (2013) Static and dynamic mechanical properties of alkali-treated unidirectional continuous palmyra palm leaf stalk fibre/jute fibre reinforced hybrid polyester composites. Mater Des 50:533-542

Sreekala MS, Kumaran MG, Joseph S, Jacob M, Thomas S (2012) Oil palm fiber reinforced phenol formaldehyde composites: influence of fiber surface modifications on the mechanical performance. Applied Composite Materials. 7:295-329

Stojanovic A, Venc A, Bobic I, Miladinovic S, Skerlic J (2019) Experimental optimization of the tribological behaviour of $\mathrm{Al} / \mathrm{SiC} / \mathrm{Gr}$ hybrid composites based on Taguchi's method and artificial neural network. J Braz Soc Mech Sci Eng 40(311):1-14

Tewarson A, Macaione DP (1993) Polymers and composites: an examination of fire spread and generation of heat and fire products. J Fire Sci 11:421-441

\section{Publisher's Note}

Springer Nature remains neutral with regard to jurisdictional claims in published maps and institutional affiliations. 